\title{
Distribution of persistent organochlorine pesticides in samples from the Canadian Arctic
}

SOME soil, moss, kelp and reindeer liver were collected at 5 sites in a wide range of the Canadian Arctic from $58^{\circ} \mathrm{N}$ to $81^{\circ} 31^{\prime} \mathrm{N}$ by the First Scientific Expedition of China to Canadian Arctic during April through May, 1995. The concentrations of persistent organochlorine $\mathrm{HCH}$ and DDT of these samples were determined. After sampling, the samples were extracted with appropriate solvents, analyzed by packed column gas chromatography with electron capture detector $^{[1]}$. The result of the soil sample collected from the area of Great Wall Station of China at King George Island, Antarctic in Januray 1991 was also reported.

Three isomers of $\mathrm{HCH}(\alpha-, \gamma$ - and $\delta-\mathrm{HCH})$ were detected for all the samples. $7.7 \mu \mathrm{g} / \mathrm{kg}$ $\beta-\mathrm{HCH}$ was detected only in kelp sample. $\mathrm{HCH}$ contents in the samples were 3.3-28.0 $\mu \mathrm{g} / \mathrm{kg}$ except reindeer liver. The isomer $\gamma$ - $\mathrm{HCH}$ was majority in $\mathrm{HCH}$. In early years $\alpha-\mathrm{HCH}$ highly predominated in $\mathrm{HCHs}$ insecticides, and in later years products of Lindan $(\gamma-\mathrm{HCH})$ have been introduced. Therefore, the predominance of $\gamma-\mathrm{HCH}$ in our findings could indicated a recent arrival to the Canadian Arctic. In 2 soil profiles of Eureka $\left(80^{\circ} \mathrm{N}\right)$ and Resolute $\left(74^{\circ} 43^{\prime} \mathrm{N}\right)$, the vertical profiles of $\mathrm{HCHs}$ residues in soil showed a decrease with depth of the soil, concentration of $\mathrm{HCHs}$ decreased from 12.3 to $7.9 \mu \mathrm{g} / \mathrm{kg}$ from 0 to $35 \mathrm{~cm}$ deep (Eure$\mathrm{ka}$ ) and from 9.1 to $5.7 \mu \mathrm{g} / \mathrm{kg}$ from 0 to $25 \mathrm{~cm}$ deep (Resolute), respectively. It was shown that concentration of $\mathrm{HCH}$ decreased with increase of latitude. The concentration of $\mathrm{HCHs}$ in reindeer liver was $205 \mu \mathrm{g} / \mathrm{kg}$, much higher than that in soil. This is obviously related to the fact that $\mathrm{HCHs}$ was easily accumulated in biotics and easily bioconcentrated through food chain. By analysing soil sample from Great Wall Station of China at Antarctic, $8.5 \mu \mathrm{g} / \mathrm{kg}$ of $\mathrm{HCH}$ was found, the same residue content as that from Canadian Arctic. Gregor (1989) reported that content of $\mathrm{HCH}$ in snow at Canadian Arctic was $1 \mathrm{ng} / \mathrm{kg}$, near the detecting limit of DDT.

Many studies have confirmed that the pollution of remote areas which had been little influenced by human activities may be caused by snow, drain and long-range atmospheric transportation. Inspite of regulation and prohibition of organochlorine pesticides in the most countries or areas since the 1970s, it has not decreased in environment. Therefore, effects of organochlorines on environment and biotics will last for a long time.

\section{Reference}

1 Compiler Group of Analytical Method of Environment Pollutants, The Method for Environmental Pollutant Analysis (in Chinese), Beijing: Science Press, 1980, 313-327.

\section{AN Fengchun, YANG Kewu, MO Hanhong and FANG Jingyun}

\footnotetext{
Research Center for Eco-Environmental Sciences, Chinese Academy of Sciences, Beijing 100085, China
} 